\title{
A ESQUIZOFRENIA E A CRIAÇÃO ARTÍSTICA SEGUNDO SABINA SPIELREIN
}

FÁtIMA CAROPRESO ${ }^{1}$

\section{Fátima Caropreso}

Universidade Federal de Juiz de Fora (UFJF), Professora do Departamento de Psicologia, Programa de Pós-Graduação em Psicologia, Juiz de Fora/MG, Brasil.
Resumo: $\mathrm{O}$ interesse por Sabina Spielrein tem aumentado nas últimas décadas, embora, nas publicações sobre essa autora, sua contribuição teórica à psicanálise ainda permaneça em segundo plano em relação ao interesse por sua biografia. Este artigo tem como objetivo apresentar algumas das ideias de Spielrein sobre o funcionamento mental, formuladas, sobretudo, a partir de sua análise da esquizofrenia, e comentar como ela concebe, a partir de tais hipóteses, os processos envolvidos no simbolismo e na criação artística. Baseamo-nos nas ideias apresentadas em sua dissertação sobre a esquizofrenia, de 1911, e em seu texto Destruição como causa do devir, de 1912.

Palavras-chave: Psicanálise; Sabina Spielrein; esquizofrenia; simbolismo; criação artística.

Abstract: Schizophrenia and artistic creation according to Sabina Spielrein. The interest in Sabina Spielrein has increased during the last decades, although, in specialized literature, her theoretical contributions to psychoanalysis still remain in the background if compared with the interest in her biography. The objective of this article is to present some of Spielrein's ideas on the mental functioning which were mainly based on her analysis of schizophrenia and to discuss how, starting from these hypotheses, she conceives the processes involved in symbolism and artistic creation. This discussion is based on her 1911 dissertation on schizophrenia and on her 1912 paper Destruction as cause of come-into-being.

Key-words: Psychoanalysis; Sabina Spielrein; schizophrenia; symbolism; artistic creation.

DOI - http://dx.doi.org/10.1590/S1516-14982018002012

Todo o conteúdo deste periódico, exceto onde estiver identificado, está licenciado sob uma Licença Creative Commons (cc by 4.0)

\footnotetext{
${ }^{1}$ Bolsista de Produtividade em Pesquisa do CNPQ.
} 
$S^{a}$ bina Nikolaevna Spielrein nasceu em 25 de outubro de 1885 na cidade russa de Rostov, nas margens do rio Don. Na puberdade, ela desenvolveu transtornos neuróticos e, em agosto de 1904, foi internada no Hospital Psiquiátrico Burghölzi, da Universidade de Zurich, onde recebeu o diagnóstico de psicose histérica. 0 seu tratamento durou nove meses e meio, e foi realizado por Carl Gustav Jung, com quem acabou se envolvendo afetivamente no ano de 1908. Ambos escreveram cartas a Freud relatando seu relacionamento. $\mathrm{Na}$ época da internação de Spielrein, o diretor do Burghölzi era Eugen Bleuler, o qual criara um clima propício para a psicanálise no hospital, incentivando colaboradores e praticantes a lerem os escritos de Freud e a experimentarem as novas ideias psicanalíticas. Spielrein foi a primeira paciente que Jung tratou com o método psicanalítico. No primeiro semestre de 1905, ela ingressou no curso de medicina da Universidade de Zurich e, em 1911, obteve o grau de doutora, tendo-se especializado em psiquiatria (RICHEBÄCHER, 2012). Ela frequentou a Sociedade Psicanalítica de Viena entre outubro de 1911 e março de 1912 (BALSAM, 2003). Sua tese médica Sobre o conteúdo psicológico de um caso de esquizofrenia (Dementiapraecox), desenvolvida sob a supervisão de Bleuler, foi publicada, em 1911, no JahrbuchfürpsychoanalytischeundpsychopathologischeForschungen. Seu primeiro artigo teórico, intitulado $A$ destruição como origem do devir, foi publicado em 1912, também no Jahrbuch. Nos anos que se seguiram, ela publicou outros artigos psicanalíticos. Cifali (2001) comenta que Spielrein foi a mulher mais jovem a escrever sobre psicanálise ${ }^{2}$. Jung e Freud a encorajavam a escrever, fato este considerável, pois, embora mulheres fossem aceitas como psicanalistas, elas eram principalmente conhecidas por serem clínicas e não teóricas (CIFALI, 2001). Em 1923, Spielrein deixou a Suíça e, após passar um ano em Moscou, retornou para Rostov, onde viveu até 1942, quando foi assassinada pelos nazistas.

O interesse por Sabina Spielrein tem aumentado desde a publicação, em 1980, por Aldo Carotenuto (1980), das suas cartas a Jung e a Freud, assim como de seus diários e documentos que tinham permanecido guardados nos porões da Biblioteca do Instituto de Psicologia da Universidade de Genebra desde sua partida para a União Soviética, em 1923. No entanto, as publicações sobre ela enfatizam, sobretudo, aspectos de sua biografia, de forma que suas hipóteses teóricas têm permanecido, a maior parte das vezes, em segundo plano (CROMBERG, 2012).No Brasil, recentemente foi publicado o primeiro volume das obras completas de Sabina Spielrein (CROMBERG, 2014), o qual contém traduções de alguns de seus mais importantes trabalhos, além de textos comentando aspectos de sua biografia e produção teórica, o que representa uma enorme contribuição para aqueles que se interessam pela história da psicanálise.

Este artigo tem como objetivo apresentar algumas das ideias de Spielrein sobre o funcionamento mental, formuladas, sobretudo, a partir de sua análise da esquizofrenia, e comentar como ela concebe, a partir de tais hipóteses, o simbolismo e o processo envolvido na criação artística. Basearemo-nos nas ideias apresentadas em seu texto sobre a demência precoce de 1911 e no texto A destruição como origem do devir, de 1912.

\section{A ESQUIZOFRENIA E O FUNCIONAMENTO MENTAL}

Em sua tese de psiquiatria Sobre o conteúdo psicológico de um caso de esquizofrenia (Dementiapraecox) (SPIELREIN, 1911), Spielrein analisa o caso de uma paciente diagnosticada com demência paranoide e busca compreender o significado das suas falas com o intuito de obter uma visão mais profunda de seus processos psíquicos. Como aponta Skea (2006), esse trabalho de Spielrein revela a influência de Bleuler e, sobretudo, de Jung. Na parte final do texto, ela argumenta que Freud e Jung já haviam demonstrado a existência de um paralelismo especial entre os fenômenos neuróticos e oníricos e as manifestações da esquizofrenia, e que ela acredita poder acrescentar dados relevantes ao conceito Freud-Jungiano com uma visão filogenética.

${ }^{2}$ Em 1911, quando sua monografia sobre a demência precoce foi publicada, Spielrein tinha 26 anos, Hermine HugHellmut tinha 40 anos e Lou Andréas-Salomé, 50 (CIFALI, 2001). 
O ser humano, diz ela, possuiria duas vivências, uma consciente e outra inconsciente, e esta última seria a responsável pela criação de uma tonalidade afetiva. Seria somente com a união do inconsciente à vivência consciente que a última se tornaria uma vivência real. Por exemplo, gostamos de um conto de fadas ou de um poema qualquer porque representações carregadas de prazer são incitadas por ele, de forma que o prazer é vivenciado quando o novo conteúdo da representação entra em contato com o antigo. Nesse caso, teríamos a impressão de que o sentimento de prazer faz parte do conteúdo atual da representação, pois nos alegraríamos com ele no presente. Contudo, na verdade, nossa alegria pertenceria às vivências passadas, as quais não diriam respeito apenas às nossas experiências pessoais, mas também às vivências ancestrais. Assim, Spielrein sustenta que "herdamos também a sedimentação das vivências de nossos ancestrais dentro de nós" (SPIELREIN, 1911/2014, p. 213). Modos de pensamento muito antigos influenciariam nossa consciência do presente.

Sobre o mecanismo da demência paranoide, Spielrein argumenta que a doente parte de seus conflitos presentes. Por exemplo, sua paciente repugnava as relações sexuais com seu marido. A reflexão consciente sobre este fato consideraria diversas possibilidades do mundo real que poderiam ajudá-la a se livrar da situação desagradável. No entanto, a esquizofrenia faz justamente o contrário, ao substituir o mundo externo real por um mundo interno com valor de realidade. Este fato já havia sido demonstrado por Jung, reconhece Spielrein, no entanto, o material de sua paciente mostra que esse Eu profundo que se expressa na doença pertence "a um passado que ultrapassa o âmbito do indivíduo" (SPIELREIN, 1911/2014, p. 215). A paciente insere sua vivência presente nesse passado. Em vez de dizer "eu fui maculada durante o ato sexual", ela diz "a terra foi perfurada". Assim, sua dor é diluída entre as várias representações análogas que abrigamos dentro de nós como herança de nossos ancestrais, de forma que ela fala a língua do pensamento mitológico. A mulher, de maneira geral, foi maculada e não ela como indivíduo, pois os antigos viam na terra uma mulher poderosa, quase a somatória do conceito de "mulher" com a matergenetrix. Nesse processo, as características pessoais seriam eliminadas.

A concepção de Spielrein sobre o mecanismo da demência paranoide apresenta diferenças significativas em relação à concepção elaborada por Freud em sua análise do caso Schreber, presente no mesmo volume do Jahrbuch, no qual a tese de Spielrein foi publicada. Freud (1911/1975) sustenta que a demência paranoide apresenta um processo regressivo que remonta ao narcisismo, o qual corresponderia, nesse momento da teoria, a um estágio intermediário entre o auto-erotismo e o amor objetal. Assim, para ele, em tal patologia, a regressão se voltaria para a etapa de constituição do Eu, enquanto que, para Spielrein, o processo regressivo transcenderia o conteúdo egoico. Para Freud (1911/1975), os sintomas esquizofrênicos seriam uma tentativa de cura; uma retomada dos investimentos objetais, que se seguiria a uma primeira etapa regressiva, na qual os investimentos das representações de objeto seriam retirados. Para Spielrein, diferentemente, os próprios sintomas expressariam um processo regressivo, onde as relações objetais pessoais seriam transformadas em experiências impessoais, pertencentes ao passado filogenético.

Spielrein (1911/2014) argumenta que a esquizofrenia gosta de se servir de conceitos abstratos vagos, devido ao fato de que estes são extratos de várias representações concretas unitárias adquiridas por meio de longa experiência, o que faz com que sejam muito mais significativos do que designações concretas e exatas. Durante a elaboração consciente de um objeto, os conceitos abstratos poderiam ser compreendidos por cada indivíduo à sua maneira, o que faria com que eles perdessem sua especificidade. Seria justamente essa falta de especificidade que tornaria os conceitos gerais tão adequados para a vida onírica da esquizofrenia. Quanto menos circunscrito fosse um conceito, menos ele indicaria algo determinado, concreto, mas mais conteúdos de representação poderia abarcar. Assim, na esquizofrenia, os conteúdos pessoais penosos seriam transformados em símbolos. A autora formula a hipótese de que um símbolo deveria sua origem ao anseio de um complexo pela sua multiplicação; pela diluição na totalidade geral do pensamento, processo no qual as características pessoais desapareceriam. 
Em seu texto sobre a destruição de 1912, ao retomar o exemplo da fala "a terra foi perfurada", Spielrein argumenta que, em sua opinião, aí estaria o sentido da expressão simbólica. $O$ símbolo significaria o mesmo que a representação penosa, mas seria menos diferenciado enquanto representação do eu. Nós podemos pensar em muito mais conteúdos quando falamos "mulher" - já que eles só precisam se assemelhar entre si na essência - do que quando falamos na representação egoica muito mais definida de uma Martha N., exemplifica a autora. Para qualquer ser humano, as outras pessoas só existiriam na medida em que fossem acessíveis à sua psique, ou seja, apenas as características dos outros que correspondessem a nós mesmos existiriam para nós. Por exemplo, quando o sonhador se substituísse por outra pessoa, ele não estaria procurando representar a pessoa em questão. O que interessaria a ele seria apenas apresentar, na pessoa substituta, a característica que correspondesse à realização de seu desejo. Se o sonhador quisesse ser invejado por ter belos olhos, então, ele agregaria diversas pessoas com belos olhos em uma pessoa mista, de forma que o resultado seria um tipo em vez de um indivíduo. Conforme mostram os estudos de pacientes com esquizofrenia, um tipo corresponderia a formas arcaicas de pensamento, segundo Spielrein (1912/2014).

Retornando à monografia sobre a esquizofrenia, Spielrein argumenta, então, que o inconsciente dilui o presente no passado. No entanto, diz ela, sabemos que os sonhos são realizações de desejos e que, portanto, se ocupam do futuro. O futuro também é transformado em passado, pois os conflitos são representados por símbolos ancestrais, assim como solucionados pelos mesmos símbolos, como se já tivessem ocorrido e sido solucionados simultaneamente. Dessa maneira, poderíamos ver no inconsciente algo que estaria fora do tempo, ou que seria, ao mesmo tempo, presente, passado e futuro, de forma que:

O inconsciente nos fornece indícios sobre os conflitos pessoais no presente, sobre os conflitos do passado filogenético a partir do qual se originam as vivências pessoais e, eventualmente, sobre o desenvolvimento futuro das coisas, já que o futuro emerge do passado (na verdade, ele é apenas uma forma do passado). (SPIELREIN, 1911/2014, p. 216)

Essas hipóteses apresentadas em 1911 são retomadas e desenvolvidas no texto $A$ destruição como origem do devir (1912). Neste texto, Spielrein argumenta que a característica principal de um indivíduo é ser um "divíduo", isto é, um ser dividido. Ela cita a hipótese de Ernst Mach, segundo a qual o ego seria apenas um agrupamento momentâneo de sensações dos elementos eternamente existentes; seria algo em contínua mudança e totalmente não essencial. A autora diz acreditar que o nome de Mach está intimamente associado ao de Carl Jung, para quem a psique seria composta por muitos entes singulares; por complexos que lutariam entre si pela prioridade. A mais esplêndida confirmação dessa visão, diz ela, é fornecida pelos doentes com demência precoce cujos egos vivenciam tão fortemente os poderes dos complexos ativados que consideram seus próprios desejos inconscientes como seres vivos hostis.

Em seu texto de 1911, seguindo as ideias de Jung, ela define um complexo como "grupos de representações carregadas de sentimentos" (SPIELREIN, 1911/2014 p. 145). A característica da demência precoce mencionada acima é ilustrada a partir do caso da sua paciente, a qual, em certo momento, se irritava com más "suposições" que as pessoas faziam a seu respeito e achava que a suposição poderia se tornar realidade a fim de substanciar seu direito à existência. Essas suposições, esclarece Spielrein, expressam os próprios complexos da paciente. Esta sentia tão intensamente o poder de seus complexos sobre si que os enxergava como seres vivos e autônomos, como seres que poderiam ser tornar vivos devido à sua vontade. A suposição, no sentido adotado pela paciente, seria uma imposição de certas intenções, ou seja, de determinados complexos, que, como grupos de representações carregadas de afeto, demandariam grande influência sobre as ações. Dessa forma, seria possivel que, em determinadas circunstâncias, as suposições se tornassem realidade, uma vez que elas não seriam meras possibilidades aleatórias, mas tornariam os complexos objetivamente conscientes, ou seja, os transformariam em grandezas psíquicas, as quais já ansiariam naturalmente por moldar a realidade segundo sua imagem. Assim, de acordo com Spielrein: "um 
complexo sempre representa uma possibilidade que adquire direito à existência por meio de ativação especial, ou seja, se torna realidade" (SPIELREIN, 1911/2014, p. 146).

Em seu texto sobre a destruição, ao retomar as hipóteses apresentadas em 1911, Spielrein argumenta que um evento adquiriria tonalidade emocional apenas na medida em que pudesse estimular tonalidades emocionais de conteúdos previamente vivenciados, que residiriam ocultos no inconsciente. Por este motivo, nós experimentaríamos muito pouco no presente. Nossas experiências conscientes seriam apenas alegorias de experiências primitivas desconhecidas que buscariam análogos no presente. Dessa maneira, pensamentos e representações inconscientes acompanhariam cada representação ou pensamento consciente e transformariam os produtos do pensamento consciente em uma linguagem específica. Este último processo de transformação é denominado "assimilação" ou "dissolução".

Os conteúdos da consciência se diferenciariam do inconsciente e, neste último, seriam assimilados, o que determinaria a tonalidade emocional de uma experiência. No inconsciente, cada representação diferenciada seria dissolvida, ou seja, transformada em um estado indiferenciado. Spielrein (1912/2014) retoma a fala de sua paciente mencionada anteriormente para exemplificar esse processo. A terra representaria a grande mãe ou a representação inconsciente de todas as pessoas. Nessa grande mãe (o inconsciente), a paciente transformaria a si mesma em sua mãe (terra) indiferenciada.

Spielrein distingue, assim, entre uma "psique do Eu" (Ichpsyche) e outra mais profunda, denominada "psique da espécie" (Artpsyche). Além de conter experiências do passado individual, o inconsciente conteria experiências de inúmeras gerações, de forma que a assimilação inconsciente de eventos que tivessem ocorrido em muitas gerações se encaixaria na cadeia de pensamentos do presente, ou seja, transformaria uma experiência do Eu em uma experiência da espécie. Quanto mais nos aproximássemos de nossos pensamentos conscientes, mais diferenciadas seriam nossas representações, ao passo que, quanto mais penetrássemos no inconsciente, mais universais e típicas elas seriam. Segundo a autora: "o âmago da nossa psique não conhece o Eu, mas apenas seu somatório, o nós, ou o Eu presente, visto como objeto, é subordinado a outros objetos semelhantes". (SPIELREIN, 1912/2014, p. 238). Assim, uma parte individual da personalidade poderia ser tomada como objeto.

Alguns autores apontam a relação existente entre o conceito de "psique da espécie" de Spielrein e o conceito junguiano de inconsciente coletivo. Como comenta Skea (2006), a emergência da ideia junguiana de inconsciente coletivo pode ser vista já no texto Significação do pai, de 1909, embora ela tenha se concretizado na segunda parte de Metamorfoses e símbolos da libido (1912), onde é empregado o termo "modos arcaicos de adaptação". Contudo, o termo "inconsciente coletivo" foi usado por Jung, pela primeira vez, apenas em Estrutura do inconsciente, de 1916. Skea (2006) defende que Spielrein teve uma importante contribuição na então emergente teoria junguiana do inconsciente coletivo. Na segunda parte de Metamorfoses e símbolos da libido, publicada no Jahrbuch no mesmo volume de 1912 em que o texto de Spielrein sobre a destruição foi publicado, Jung se refere dezessete vezes ao estudo de Spielrein sobre a demência precoce de 1911, citando material do delírio da paciente que ela havia relacionado com o nível mitológico do inconsciente. No entanto, a tradução para o inglês de 1916 e todas as edições subsequentes, culminando em Símbolos da transformação (1952), datam incorretamente o texto de Spielrein como sendo de 1912. Skea (2006) comenta ainda que, embora Jung tenha mantido a maior parte das referências ao trabalho de Spielrein em Símbolos da transformação, ele retirou a única referência a ela presente na primeira parte de Metamorfoses e símbolos da libido (1911). Nessa referência, ele mencionava a interessante correlação entre formas patológicas e mitológicas reveladas nas investigações analíticas de Spielrein e enfatizava expressamente que ela havia descoberto o simbolismo aí presente através de seu trabalho, independente e sem conexão com suas ideias. Skea (2006) considera que, com a hipótese de "psique da espécie" apresentada em seu texto sobre a destruição de 1912, Spielrein antecipa em quatro anos a definição de inconsciente coletivo de Jung e que isso 
nunca foi reconhecido por ele. Van Waning (1992) também afirma que Spielrein antecipou o conceito junguiano de inconsciente coletivo.

Em seu texto de 1912, Spielrein continua desenvolvendo suas hipóteses de 1911, argumentando que, na esquizofrenia, como consequência da falta de atividade do Eu, as representações deste seriam transformadas em representações da espécie (Artvorstellungen) ou objetivas. Tal patologia poderia ser interpretada, então, como uma batalha entre as duas tendências antagônicas da psique. De acordo com Spielrein: "a psique da espécie quer transformar a representação do Eu em uma representação tipicamente impessoal, a psique do Eu defende-se dessa diluição (...)" (SPIELREIN, 1912/2014, p. 240).

Dessa maneira, duas tendências opostas - uma "tendência à dissolução e assimilação" e uma "tendência à diferenciação" - estariam presentes no psiquismo, as quais seriam expressões psíquicas das pulsões de conservação da espécie (Arterhaltungstrieb) e de autoconservação (Selbsterhaltungstrieb), respectivamente. Assim, a oposição - sustentada ainda por Freud na época - entre estes dois tipos de pulsões é mantida. No entanto, Spielrein insere o instinto de morte no interior do instinto sexual e o coloca como condição para a criação.

\section{A HIPÓTESE DO INSTINTO DE MORTE}

No início de seu texto de 1912, Spielrein levanta a questão sobre por que razão a pulsão de reprodução (Fortpflanzungstrieb), a mais poderosa das pulsões, pode trazer consigo sentimentos negativos - tais como ansiedade e desgosto - ao lado de sentimentos positivos. "O que acontece ao indivíduo na presença da atividade sexual que justifica este estado mental?", pergunta-se ela. Uma série de autores que apontaram essa relação e tentaram explicá-la são mencionados, no entanto, Spielrein formula uma hipótese própria para respondê-la: "tais sentimentos correspondem aos componentes destrutivos do instinto sexual" (SPIELREIN, 1912/2014, p. 232). Adiante, Spielrein fala em um "instinto de morte no instinto sexual" (SPIELREIN, 1912, p. 259).

Essa ideia de uma relação necessária entre sexualidade e destruição já estava insinuada nos extratos do diário de Sabina (SPIELREIN, 2003). No prólogo deste último texto, Jeanne Moll afirma que há indícios de que o mesmo tenha sido escrito entre os anos de 1906 e 1907, embora não seja possível estabelecer com precisão a data de escrita. Em carta a Freud, escrita em 1909, Spielrein também já havia mencionado sua teoria sobre a relação entre sexualidade e destrutividade (CAROTENUTO, 1980).

A conclusão sobre a necessidade de supor um componente destrutivo nos instintos sexuais é enunciada após uma breve reflexão sobre alguns fatos biológicos. Na reprodução, as células unitárias são destruídas, dando origem a uma nova vida. Alguns seres inferiores morrem após se reproduzirem. No caso dos seres multicelulares, a diferença seria apenas quantitativa: uma parte do organismo (células germinativas), que representa o organismo inteiro, é destruída. Nesse caso, o componente masculino funde-se ao componente feminino, o qual é reorganizado e assume uma nova forma mediada pelo intruso desconhecido. Assim, diz ela:

(...) destruição e reconstrução, as quais sempre ocorrem mesmo em circunstâncias normais, ocorrem bruscamente. O organismo descarrega os produtos sexuais como qualquer uma de suas excreções. É improvável que o indivíduo não tenha no mínimo uma suspeita, traduzida em afetos correspondentes, sobre a existência desses processos de destruição e reconstrução em seu organismo. Assim como os próprios afetos de bem-estar associados ao devir estão presentes na pulsão de procriação, os afetos de defesa, como angústia e aversão (...), correspondem aos componentes destrutivos do instinto sexual. (SPIELREIN, 1912/2014, p. 232) ${ }^{3}$

${ }^{3}$ Spielrein (1912) usa os termos Instinkt, Trieb e Drang ao longo do texto. Ela usa Instinkt nos substantivos compostos Todesinstinkt (instinto de morte) e Sexualinstinkt (instinto sexual). O termo Drang é usado em Destruktionsdrang (impulso de destruição) e o termo Trieb é usado em Selbsterhaltungstrieb (pulsão de 
O instinto sexual e o instinto de morte a ele associado trabalhariam no sentido da conservação da espécie e dariam origem à tendência à dissolução e assimilação, à qual se oporia a tendência à diferenciação que, como vimos, seria expressão da pulsão de autoconservação. Enquanto a primeira dessas tendências visaria transformar a experiência do Eu em uma experiência da espécie, a segunda visaria manter a inércia da personalidade do Eu. Nas palavras da autora:

A pulsão de autoconservação em nós corresponde à tendência de diferenciação e à capacidade de perseveração de uma partícula do Eu cristalizada externamente ou de toda a personalidade do Eu. A pulsão de conservação da espécie é uma pulsão de procriação, e ela se expressa também psiquicamente na dissolução e na tendência à assimilação (transformação do Eu em um Nós) com a consequente nova diferenciação a partir da matéria original. Onde o amor reina, o morre, esse déspota tenebroso. (SPIELREIN, 1912/2014, p. 260-261)

Como não haveria devir sem destruição, a conservação das espécies daria origem à tendência à dissolução e assimilação, da qual dependeria a criação. A pulsão de autoconservação não daria origem a nada de novo, uma vez que visaria manter a inércia do Eu. Assim, Spielrein argumenta que:

A pulsão de autoconservação é uma pulsão simples, composta apenas de um lado positivo, a pulsão de conservação da espécie, que precisa dissolver o antigo para que o novo surja, é composta de um componente positivo e um negativo. A pulsão de conservação da espécie é, por essência, ambivalente; por isso, o estímulo dos componentes positivos provoca, ao mesmo tempo, o estímulo dos componentes negativos, e vice-versa. A pulsão de autoconservação é uma pulsão "estática", na medida em que deve proteger o indivíduo que já existe contra influências externas. A pulsão de conservação da espécie é uma pulsão "dinâmica" que anseia pela alteração, pela "ressurreição" do indivíduo em uma nova forma. Nenhuma alteração pode acontecer sem o aniquilamento do estado antigo. (SPIELREIN, 1912/2014, p. 261)

É frequente a afirmação de que Spielrein teria antecipado o conceito freudiano de pulsão de morte proposto em 1920, em Além do princípio do prazer (LOTHANE, 2003; BRITTON, 2003; VAN WANING, 1992; ROBERT, 1966; CAROTENUTO, 1980; PERES, 2012). No entanto, embora não seja possível negar que Freud tenha sido, de alguma forma, influenciado pelas hipóteses de Spielrein, pode-se argumentar que há diferenças significativas entre o instinto de morte proposto pela psicanalista e a pulsão de morte freudiana ${ }^{4}$. A primeira delas é o fato de que, enquanto Spielrein defende a existência de um instinto de morte "no" instinto sexual, Freud(1920/1975) sustenta que a pulsão sexual pertence à classe das pulsões de vida, às quais se oporia outro grupo de pulsões opostas que trabalhariam a serviço da morte do organismo. Assim, ele não aceita a existência de uma pulsão de morte interna à pulsão sexual, embora reconheça a relação íntima entre sexualidade e destrutividade manifesta, sobretudo, nos fenômenos do sadismo e do masoquismo. Dessa maneira, o que Freud explica a partir da vinculação entre a pulsão de morte e a pulsão sexual - as quais corresponderiam a duas classes de pulsões independentes e opostas -, Spielrein explica a partir de uma intensificação do componente destrutivo do próprio instinto sexual. Como aponta Kerr (1988), para Spielrein, a sexualidade seria inerentemente ambivalente e a morte estaria contida em sua dialética. Já, para Freud, a tendência para a morte seria manifestação primária de um instinto de morte independente da libido.

Outro ponto importante de distinção entre os dois autores é que justamente por supor um instinto de morte no instinto sexual, Sabina considera o impulso destrutivo indissociável de um impulso reprodutivo, os quais se expressariam na tendência à dissolução e assimilação. Assim, para ela, a destruição impulsionada

autoconservação), Arterhaltungstrieb (pulsão de conservação da espécie) e Fortpflanzungstrieb (pulsão de procriação). Ela usa também, em poucas ocasiões, Fortpflanzungsinstinkt (instinto de procriação) e Selbsterhaltungsinsinkt (instinto de autoconservação).

${ }^{4}$ No sexto capítulo de Além do princípio do prazer (FREUD, 1920/1975), ao comentar a hipótese de que o masoquismo pode ser primário em relação ao sadismo, Freud insere uma nota dizendo: "Uma porção considerável dessas especulações foi antecipada por Sabina Spielrein (1912) em um interessante e instrutivo artigo, o qual, contudo, infelizmente, não é inteiramente claro a mim" (FREUD, ibidem, p. 55). 
pelo instinto de morte seria indissociável da criação de algo. Podemos dizer que a destruição seria condição para o surgimento do novo e o traria consigo necessariamente. Por este motivo, ela considerava que a pulsão de preservação das espécies surgiria de componentes positivos e negativos. Já, para Freud (1920/1975), a pulsão de morte visaria, em última instância, o retorno ao inorgânico, à aniquilação da vida, e não teria como consequência necessária, portanto, a criação. Freud explica a preservação e o desenvolvimento da vida a partir da ação das pulsões de vida, ou seja, a partir de outra classe de pulsões independentes. Assim, a pulsão de morte, por si só, conduziria à aniquilação da vida. Ela não traria algo novo como consequência da destruição; ela não seria "criativa". Neste sentido, é que podemos dizer que, para Freud, a pulsão de morte seria puramente negativa, diferentemente do que sustenta Spielrein.

Além de propor que a destruição é indissociável da criação, para Spielrein, o instinto de morte visaria à aniquilação da psique egoica e sua submissão à psique da espécie. Não se trataria, portanto, da destruição da vida como um todo, mas da destruição do egoico. Este é outro ponto significativo que distancia os conceitos dos dois autores. A diferenciação entre psique egoica e da espécie e a suposição de que a primeira buscaria sobrepor-se à segunda não encontra paralelo na teoria freudiana.

Podemos dizer, portanto, que, com seu conceito de instinto de morte, Sabina Spielrein antecipa a hipótese de que existe "um" instinto de morte no psiquismo; no entanto, entre a sua hipótese e o conceito freudiano de pulsão de morte há diferenças fundamentais que distanciam o pensamento dos dois autores.

Segundo Spielrein (1912), o processo de dissolução e assimilação poderia ser vivido de forma prazerosa ou desprazerosa. Na esquizofrenia, a transformação das representações do Eu em representações da espécie daria origem inicialmente à ansiedade e depressão severas. Tais sentimentos surgiriam enquanto o paciente se empenhasse em sustentar uma relação egoica. Com a progressão da doença, a indiferença se instalaria. Já, no envolvimento com o sexo oposto, a dissolução do ego no amado seria vivida com alegria. Também a experiência artística envolveria a transformação do egoico no coletivo e, nesse caso, esta seria vivida com regozijo.

\section{A CRIAÇÃO ARTÍSTICA COMO PROCESSO DE TRANSFORMAÇÃO E DESTRUIÇÃO DO EU}

Em Destruição como origem do devir (1912), Spielrein argumenta que a psique da espécie, a qual nega o Eu atual, consegue criá-lo novamente por meio da negação, pois a partícula do Eu submersa volta a emergir através de novas representações, mais rica do que antes. Tal processo poderia ser visto de forma belíssima nas produções artísticas.

O indivíduo buscaria aquilo que é semelhante a si mesmo (os pais, ancestrais) no qual a própria partícula do Eu pudesse ser diluída, o que significaria a morte para esta última. No entanto, esta última voltaria a aparecer sob uma nova forma, talvez mais bela, mas não seria mais a mesma, mas, sim, um outro criado à custa desta última, assim como uma árvore que crescesse a partir de uma semente seria a mesma no que diz respeito à espécie, mas não a mesma no que diz respeito ao indivíduo. Na verdade, diz ela, é uma questão de ponto de vista se, nos novos produtos que emergem à custa dos antigos, focalizamos a existência ou o desvanecer da antiga vida. Assim, como aponta Witt (1995), Spielrein desenvolve a ideia de transformações individuais através da destruição, concebida como dissolução ou desintegração da psique do Eu individual em uma psique geral da espécie.

A regressão no âmbito do Eu consistiria no fato de a pessoa querer reviver experiências infantis carregadas de prazer. Mas por que, pergunta-se ela, experimentamos alegria ao reconhecer o conhecido? Por que a severa censura continua existindo mesmo quando não sentimos mais o poder dos pais sobre nós? Por que não experimentamos sempre o mesmo e reproduzimos o mesmo? Por que o artista, por exemplo, não pinta sempre a imagem de sua amada mãe, mas cria eventualmente um quadro renascentista, uma vez que a "censura" não nos proíbe de amar a mãe de forma sublimada? Ela responde a estas questões dizendo que 
isso se deve ao fato de haver dentro de nós, paralelamente ao desejo de manter nossa condição presente, um desejo pela transformação. Em suas palavras:

Há dentro de nós, paralelamente ao desejo de perseverar, um desejo de transformação, sendo que este último significa que um conteúdo representacional individual é diluído em um material semelhante a ele, proveniente de tempos passados e que, portanto, deve se transformar à custa do indivíduo em um desejo típico, ou seja, um desejo da espécie, o qual é projetado para fora pelo indivíduo como obra de arte. (SPIELREIN, 2012/2014, p. 242)

Assim, para se expressar, o artista diluiria um conteúdo representacional individual em um material da espécie e o projetaria em sua obra. Esse processo seria impulsionado pelo desejo de transformação oriundo da tendência à dissolução e assimilação da psique da espécie. Assim, o instinto de morte estaria por trás desse processo.

Como comenta Cromberg (2014), em seu texto de 1912, a partir da criação artística, Spielrein passa a pensar a palavra enquanto representação e símbolo. Ela comenta que tudo o que nos comove quer ser comunicado, compreendido e igualmente sentido, e que "cada representação que transmitimos aos nossos semelhantes, diretamente ou na forma de uma obra de arte, é produto da diferenciação das vivências primevas que compõem nossa psique" (SPIELREIN, 1912/2014, p. 243). Como exemplo, a autora menciona uma vivência já diferenciada como um dia ensolarado de primavera que, antes de nós, alegrou muitas vezes infinitas gerações. Ao reproduzirmos essa vivência, precisaríamos diferenciar, dando forma às árvores, à grama e ao céu de acordo com o conteúdo atual de nosso consciente. Nesse caso, nós não estaríamos mais lidando com um dia de primavera, mas com o dia de primavera especial, que teria um tom pessoal. 0 processo inverso ocorreria se esse produto da diferenciação chegasse à psique de outro indivíduo. Durante o processamento consciente por parte de outro indivíduo, o dia de primavera adquiriria outra estampa individual. Paralelamente ao processamento consciente, a representação passaria pelo processamento inconsciente que eliminaria sua estampa individual atual e as diluiria. No inconsciente, diz ela, talvez nós encontremos o dia de primavera desmantelado em seus componentes (o sol, o céu, as plantas) e transformado em imagens mitológicas da psicologia dos povos, ou seja, restaurado à sua forma original.

Dessa forma, toda representação buscaria por um material não idêntico, mas semelhante, no qual pudesse ser diluída e transformada. Esse material semelhante seria a compreensão baseada nos mesmos conteúdos de representação com a qual a outra pessoa receberia nossa representação. Ao expressarmos em palavras um pensamento referente à descrição de uma representação, nós já realizaríamos uma generalização, pois as palavras seriam símbolos que serviriam para formatar o que é pessoal, ou seja, para eliminar a estampa pessoal. A partir dessas ideias, Spielrein argumenta que:

Aquilo que é puramente pessoal nunca pode ser compreendido por outros, e não nos espanta quando Nietzsche, um homem com uma poderosa consciência do Eu, chega à conclusão de que a língua existe para confundir a nós e aos outros. Mas mesmo assim, sentimos alívio ao nos pronunciarmos quando criamos uma representação da espécie à custa de nossa representação do Eu e o artista se alegra com seu produto sublimado quando cria, ao invés do individual, o típico. (SPIELREIN, 1912/2014, p. 244)

Assim, como comenta Cromberg (2014), a palavra seria uma mediação entre algo estritamente individual e aquilo que é comum a todos os homens. O pensamento representacional por meio de palavras se daria por um trabalho que visaria a uma generalização, à compreensão e à acessibilidade aos outros e, ainda assim, almejaria manter sua singularidade. No entanto, a linguagem, ou qualquer forma de expressão, artística ou não, traria o alívio real do processo sublimatório que dissolveria o individual no comum a toda a espécie, trazendo à tona o típico, mais que o individual.

A partir das hipóteses apresentadas em seu texto sobre a destruição, podemos dizer que, para Spielrein, a criação artística, como qualquer processo de criação, teria como condição a destruição de algo e, nesse 
sentido, seria impulsionada pelo instinto de morte contido na pulsão de conservação da espécie. Assim como a esquizofrenia, a criação artística envolveria um processo de dissolução do conteúdo do Eu naquele da espécie. No entanto, no caso do artista, haveria uma diferença importante. Como observa Smith (2012), enquanto pacientes esquizofrênicos se defenderiam de suas experiências individuais transformando-as em símbolos coletivos, os artistas usariam tais símbolos na produção de sua arte a fim de serem capazes de transmitir suas experiências aos outros. Dessa maneira, como comenta Cromberg (2014), na esquizofrenia, a dissolução do Eu transformaria as representações individuais em representações impessoais projetadas no fenômeno alucinatório, em um movimento que estancaria a transformação e a renovação do Eu. Este desapareceria e a alucinação apenas projetaria os conteúdos afetivos em um material que não estabeleceria relação com o outro. Já na criação artística, esse mesmo processo de dissolução seria usado para estabelecer uma comunicação com o mundo externo.

O processo de dissolução, segundo Spielrein, faria com que um conteúdo egoico fosse transformado em um conteúdo da espécie. Como vimos acima, Spielrein argumenta que esse processo significaria a morte da partícula egoica. No entanto, como a morte ou a destruição trariam sempre algo novo como consequência, tal destruição do Eu significaria ao mesmo tempo o surgimento de um novo produto. Embora Spielrein sustente que tanto a criação artística quanto a esquizofrenia envolvam esse processo de dissolução, na segunda, a dissolução seria impulsionada por uma necessidade de fuga de um sofrimento pessoal. Na medida em que as falas e alucinações presentes nessa patologia não são compreendidas de imediato pelos outros, pode-se dizer que aí a comunicação com o mundo externo é perdida. Já na criação artística, esse mesmo processo de dissolução teria como consequência um produto que produziria um efeito estético sobre os outros, estabelecendo, nesse sentido, uma forma de comunicação. Assim, enquanto no caso do artista o processo de dissolução seria usado para expressar suas experiências pessoais - mesmo que tal expressão ocorra pela dissolução dessas experiências em um conteúdo coletivo -, na esquizofrenia, o processo de dissolução visaria a uma fuga das experiências pessoais e a dissolução traria como produto falas e alucinações que não estabeleceriam, em princípio, nenhuma forma de comunicação, embora, como chama atenção Spielrein, seja possível interpretá-las e resgatar assim o seu sentido.

\section{CONSIDERAÇÕES FINAIS}

Em sua monografia sobre a esquizofrenia, Spielrein introduz a hipótese de que o inconsciente contém sedimentos de vivências do passado filogenético e de que a esquizofrenia envolve um processo de dissolução de um conteúdo pessoal em experiências impessoais pertencentes ao passado filogenético. As ideias aí elaboradas são desenvolvidas no texto de 1912, dando origem à distinção entre psique do Eu e psique da espécie, sob o pano de fundo da qual a ideia de um instinto de morte é formulada. Nesse texto, Spielrein propõe também algumas hipóteses sobre o simbolismo e a criação artística.

Segundo Spielrein, a psique da espécie e a psique do Eu apresentariam duas tendências antagônicas. A primeira conteria uma tendência à dissolução e assimilação - expressão psicológica da pulsão de conservação das espécies -, que visaria subsumir o conteúdo do Eu ao da espécie. A segunda manifestaria uma tendência à diferenciação - expressão psicológica da pulsão de autoconservação -, que visaria manter a inércia do Eu. Enquanto a tendência à dissolução e assimilação se fundamentaria em componentes positivos e negativos, a tendência à diferenciação se basearia apenas em componentes positivos. Como não haveria criação sem destruição, o surgimento de algo dependeria da primeira dessas tendências. Dela dependeria todo processo criativo.

Na esquizofrenia, a transformação do egoico em um símbolo coletivo seria usada como meio de fuga das experiências individuais. Na arte, esse mesmo processo de dissolução e transformação de conteúdos egoicos permitiria ao artista expressar algo de si mesmo e se comunicar com os outros. Uma partícula egoica se 
dissolveria e se transformaria, aniquilando-se para dar lugar a um novo conteúdo capaz de produzir um efeito estético sobre outros indivíduos. Paradoxalmente, para se expressar, seria preciso dissolver-se em um conteúdo coletivo. Dessa maneira, segundo o pensamento de Spielrein, a criação artística seria impulsionada pelo instinto de morte; seria um processo de destruição e transformação do egoico no coletivo, que estaria na base de todo o simbolismo e de toda forma de comunicação entre os indivíduos.

Recebido em: 23 de outubro de 2015. Aprovado em: 24 de abril de 2016.

\section{Referências}

BALSAM, R. M. Women of the Wednesday Society. American Imago, v. 60, n. 3, 2003, p. 303-342.

BRITTON, R. Sex, death and the superego: experiences in psychoanalysis. London: Karnac Books, 2003.

CAROTENUTO, A. A secret symmetry, Sabina Spielrein between Jung and Freud. New York: Pantheon Books, 1980.

CIFALI, M. Sabina Spielrein, a woman psychoanalyst: another picture. Journal of Analytical Psychology, v. 46,2001, p. $129-138$.

CROMBERG, R. A autoria de Sabina Spielrein. Jornal de Psicanálise, v. 45, n. 8, 2012, p. 83-98.

Sabina Spielrein: uma pioneira da psicanálise. São Paulo: Livros da Matriz, 2014.

FREUD, S. Beyond the pleasure principle (1920). Londres: Hogarth Press, 1975. (The standard edition of the complete psychological works, 8)

Psychoanalytic notes on an autobiographical account of a case of paranoia (Dementia paranoides) (1911). Londres: Hogarth Press, 1975. (The standard edition of the complete psychological works, 12)

KERR, J. Beyond the pleasure principle and back again: Freud, Jung, and Sabina Spielrein. In: STEPANSKY, P. E. (ed.). Freud appraisals and reappraisals, v. 3. Hillsdale: Analytic Press, 1988, p. 379.

LOTHANE, Z. Tender love and transference: unpublished letters of C. G. Jung and Sabina Spielrein. In: COVINGTON, C.; WHARTO, B. (eds). Sabina Spielrein: forgotten pioneer of Psychoanalysis. Nova York: Brunner-Routledge, 2003, p. 191-225.

PERES, R. S. M. Sabina Spielrein: do que não se pode falar, do que não se pode saber. Letra Freudiana, v. 11, n. 10,2012 , p. 58-62.

RICHEBÄCHER, S. Sabina Spielrein de Freud a Jung. Rio de Janeiro: Civilização Brasileira, 2012.

ROBERT, M. The Psychoanalytic revolution: Sigmund Freud life and achievement. New York: Harcourt, Brace \& World, 1966.

SKEA, B. R. S. Spielrein: out from the shadow of Freud and Jung. Journal of Analytical Psychology, v. 51, 2006, p. 527-552.

SPIELREIN, S. A destruição como origem do devir (1912). In: CROMBERG, R. U. (org.). Sabina Spielrein: uma pioneira da psicanálise. São Paulo: Livros da Matriz, 2014, p. 227-277.

.Die DestruktionalsUrsachedesWedens. Jahrbuchfürpsychoanalytischeundpsychopathologische Forschungen, v. 4, n. 1, 1912, p. 465-503.

.Sobre o conteúdo psicológico de um caso de esquizofrenia (1911). In: CROMBERG, R. U. (org.). Sabina Spielrein: uma pioneira da psicanálise. São Paulo: Livros da Matriz, 2014, p.127-216.

Unedited extracts from a diary. With a prologue by Jeanne Moll. In: COVINGTON, C.; WHARTON, B. (eds.) Sabina Spielrein: forgotten pioneer of Psychoanalysis. Nova York: BrunnerRoutledge, 2003.

SMITH, E. W. L. The psychology of artists and the art. Jefferson: McFarland\& Company, 2012.

VAN WANING, A. The works of pioneering psychoanalyst Sabina Spielrein - Destruction as a cause of coming into being. International Review of Psycho-Analysis, v. 19, 1992, p. 399-414.

WITT, S. K. Introduction to Sabina Spielrein's "Destruction as Cause of Becoming". Psychoanalysis and Contemporary Thought, v.18, 1995, p. 75-83.

\section{Fátima Caropreso}

fatimacaropreso@uol.com.br 